\title{
Quantitative Comparison between Writing Attitudes of U.S. Domestic and International Engineering Graduate Students
}

\section{Ellen Zerbe, Pennsylvania State University, University Park}

Ellen Zerbe is a $\mathrm{PhD}$ candidate in Mechanical Engineering at Pennsylvania State University. She earned her B.S.M.E. at Grove City College. She is currently researching under Dr. Catherine Berdanier in the Engineering Cognition Research Laboratory.

\section{Dr. Catherine G.P. Berdanier, Pennsylvania State University, University Park}

Catherine G.P. Berdanier is an Assistant Professor in the Department of Mechanical Engineering at Pennsylvania State University. She earned her B.S. in Chemistry from The University of South Dakota, her M.S. in Aeronautical and Astronautical Engineering and Ph.D. in Engineering Education from Purdue University. Her research interests include graduate-level engineering education, including inter- and multidisciplinary graduate education, online engineering cognition and learning, and engineering communication. 


\title{
Quantitative Comparison between Writing Attitudes of U.S. Domestic and International Engineering Graduate Students
}

\begin{abstract}
Engineering students entering graduate school are typically underprepared for the writing tasks involved completing a Ph.D. Previous work has shown that writing attitudes and confidence in writing skills correlate with likelihood of pursuing certain careers and persistence and attrition in the program. However, all work to date has considered graduate students all together: In this study we seek to understand potential differences in the ways that U.S. domestic students and international student (both those studying in the U.S. and those studying in other countries) so that researchers and faculty who teach engineering communication can better tailor their activities and approaches to teaching writing. A survey accessing the students writing approaches, concepts, and self-regulatory efficacy was distributed to engineering graduate students at universities in Japan and Norway. The results of this survey were then compared to the results of a similar survey taken by domestic engineering graduate students and international engineering graduate students studying in the U.S. Findings indicate that there are statistically significant differences between U.S. domestic engineering graduate students with international engineering graduate students for most of the engineering writing attitudinal factors studied, indicating that instructors should begin to tailor approaches differently for individual students. From a research perspective, we will continue to use these findings to investigate and illuminate cultural variations that can influence the writing process.
\end{abstract}

\section{Introduction}

Writing is an integral aspect of graduate school, be it degree deliverables or requirements to publish, and engineering students are entering graduate school underprepared for these writing tasks. Beyond the writing demands of the graduate program, it has been shown that writing skills are critical in both industrial and academic careers $[1,2]$. But engineering graduate students rarely talk to their advisor about the writing process and many have not taken a writing intensive course within the last two years [3]. Students procrastinate on writing assignments, either because of an unfamiliarity with the writing process or by sheer aversion to writing, and this procrastination becomes a major source of anxiety $[4,5]$. Writing is a critical skill for engineering graduate students and understanding students' attitudes towards writing can lead to improved competency. Graduate engineering writing education in the United States, however, is complicated by the fact that over half of U.S. engineering graduate students are international. While most graduate programs require English proficiency exams, like the TOEFL or IELTS, these exams do not measure proficiency at disciplinary academic writing, the genre of which is "foreign" even to U.S. domestic students. With these two populations in mind, this study seeks to investigate the attitudes of graduate engineering student writers, seeking to draw comparisons and illuminate differences in the ways in which graduate engineering students conceptualize and approach the writing process in order to lend insight into pedagogical practices for faculty advisors, writing instructors, or others facilitating the success of engineering graduate students.

\section{Literature Review}

Writing studies involving engineers typically involve intervention strategies for the class or through a specialized program. Writing interventions have typically been applied directly to the students by incorporating instruction throughout a preexisting class [6], through assigning specialized assessments [7, 8], or by creating a focused writing course [9]. However, interventions 
can also be applied to faculty who will then apply what they have learned about writing to their curriculum [10]. Writing centers have also tried to facilitate improvement of engineering writing by including engineering focused support [11]. In some instances, the engineering students themselves develop a scheme for improving writing skills by creating a writing "support group" [12]. Typically, these studies focus on how the students' writing improved because of the writing instruction, rather than understanding the students' attitudes towards the writing process.

Some analysis of undergraduate engineering writing has been conducted using writing research methods, particularly genre analysis methods. For example, Fillenwarth et al. [13] studied the development on disciplinary discourse in engineering undergraduates' résumés, positing that disciplinary discourse is an important part of developing academic literacy and developing an identity within a specific field. Similarly, Conrad [14] used genre analysis to study the word choice, syntax, and sentence development in written documents of undergraduate civil engineers and compared those documents to those written by professional civil engineers. Anthony [15] analyzed how well an established writing model for introductions applied to software engineering research articles. In related technical literature, genre theory has been used to characterize rhetorical patterns undergraduate lab reports [16] and to understand the rhetorical strategy of research articles [17]. While writing research methods have been applied to engineering technical writing, mostly focusing on undergraduate students, there is a lack of research exploring graduate level engineering writing.

There is a recognized need for better writing skills in the graduate student population. Rose and McClafferty [18] unpack the need for better writing education for graduate students as they observe a graduate level writing workshop. The students in the class were from diverse disciplines and all struggled in some way with elements like grammar, fluidity, and audience awareness. The same struggles exist in engineering graduate students, who often enter graduate school with little to no formal writing instruction. Focusing specifically on engineering graduate students, Leydens and Olds [19] created a course on academic publishing. The course was designed to address the need of the department for stronger academic writing from their students. The authors developed the course with discipline specific discourse in mind. However, their work only examines the development and potential improvements to the course and does not focus on the students' understanding and approach to the writing process.

Further complicating engineering writing, over half of graduate engineering students in the U.S. are international students completing a graduate degree in the United States and therefore need to read and write academic documents in a language that may not be their first language. Writing competencies in English as a Foreign Language (EFL) students have been studied within the framework of academic literacy [20], in relation to the mentorship from the adviser [21], and in respect to the anxiety produced from the writing process [22]. All three studies focus on a more general population of graduate students, rather than limiting the population to just engineers. EFL students in engineering need writing skills beyond conversational English and need to develop the academic literacy needed for technical documents.

The attitudes that graduate student have towards the writing process influences the productivity of their writing as well as their expectations for the success of the document and beyond to their success in the program. Lonka et al. [23] assessed the well-being of graduate students based on 
their beliefs about writing. They found that adverse concepts of writing correlated with stress, anxiety, and exhaustion. Strong writing concepts and approaches have been correlated with the likelihood to pursue a wide breadth of career options whereas weaker attitudes correlated with fewer career trajectories showing that students with a lack of confidence in writing are self-limiting the career options available [3]. Without a deeper understanding of the students' relationship with the writing process, instructors and advisors may not be addressing the sources of writing anxiety and therefore indirectly impacting these students' well-being and visions of the future. The writing attitudes of engineers specifically have not been focused on engineering education or writing literature.

The current work is interpreted through an academic literacy framework [20, 21], [24, 25], which posits that academic literacy goes beyond simply the ability to read and write. Rather, it is the understanding of appropriate ways to communicate within a specific discipline that aligns with the community's expectations. Academic literacy theory is typically applied to graduate students, since they are expected to publish and their work is held to the same standards and expectations as the rest of the discipline at the same time as they are learning to operate in the expectations and norms of their communities, and learning to communicate as a member of their discipline. Writing researchers have long held the belief that the affective domain, or attitudes and feelings toward writing, can either encourage or inhibit the growth of academic literacy, perhaps affecting mechanisms of socialization into the disciplinary community. Within this framework, we seek to understand the attitudes that are shared and differ between U.S. domestic students and international students as a first step to more appropriately understanding engineering graduate student writing as it impacts graduate socialization.

The work presented in this article was developed out of this need for a comprehensive understanding of engineering graduate students' attitudes towards writing. As part of a larger study [3], this study seeks to answer two research questions:

1. What are the writing concepts, processes, and attitudes that are common among graduate engineering students at research-intensive universities in the U.S.?

2. To what extent do attitudes regarding writing differ between U.S. domestic and international students?

\section{Methods}

Participant Recruitment. Participants were recruited with two strategies. We created an online survey to assess graduate engineering students' approaches and conceptions about the writing process as well as collect demographic information. Included in the demographic information was a question regarding whether each student was a domestic student or an international student studying in the United States. In the first method, this survey was sent out to engineering graduate directors at research-intensive schools across the country. They then distributed the survey to students. Students were incentivized with a \$5 Amazon gift card for completion of the survey. In the second method of recruitment, we sent the survey directly to international students who were participating in a writing seminar in Japan and Norway. Japan and Norway were selected as countries of interest because the author was conducting a technical writing seminar in these locations. The survey sent to these students was the same survey sent through the first method, expect for some demographic questions that were modified to match the audience. All questions regarding writing attitudes were kept the same. Between the two requirement methods, there were 
$\mathrm{N}=348$ domestic participants and $\mathrm{N}=308$ international participants (in the US and abroad). The survey itself is part of a larger IRB-approved study. For this work, we will focus on two of the writing scales included in the survey, the Inventory of Graduate Writing Processes and the Graduate Concepts of Academic Writing surveys developed and validated by other researchers.

Inventory of Graduate Writing Processes [26]. The Inventory of Graduate Writing Processes scale asks multiple questions using a Likert scale regarding the student's approach to the writing process. Results from the questions were sorted into their factors and averaged with the other infactor items to find each student's primary and secondary approaches. The factors are described below.

- Elaborative - writing is a personal investment and part of knowledge creation

- Low Self-Efficacy - lack of confidence in ability to articulate thoughts

- No Revision - avoids or resists deep revision

- Intuitive - Innate sense of writing, expectations, the ability to "see" or "hear" an argument affectively

- Scientist - follows a strict order to the writing process

- Task Oriented - strong adherence to "rules" of writing and may not see writing as a personal process

- Sculptor-highly fluent style of drafting text, typically only revises after an entire draft is written

Graduate Concepts of Academic Writing [23]. The Graduate Concepts of Academic Writing scale also uses a Likert scale to measure what the student believes about the writing process. Those beliefs are sorted into the six concepts described below. Scores from each question were sorted by concept and averaged to find the primary and secondary concept, in the same manner as the other scale employed.

- Blocks - experiences writing "paralysis" that inhibits the production of text or how to begin writing

- Procrastination - puts off starting or working on writing tasks

- Perfectionism - strives toward perfection and may not make progress due to continuous revision/editing

- Innate Ability - believes writing ability is a fixed attribute that cannot be taught

- Knowledge-Transforming-believes writing is a way to build and test knowledge and arguments

- Productivity — stays on task, able to consistently make progress when writing

The survey was sorted and scored according to each scale's requirements using a MATLAB script. The script also accounted for any reverse-coded questions and calculated each participant's primary and secondary approaches and concepts. Participant scores for each attitude were compared between domestic and international students using analysis of variance methods (ANOVA).

\section{Results}

The results of the survey were calculated and each student was assigned their primary and secondary approaches and concepts. Figure 1 presents the results for the writing processes scale for both international and domestic students. Most students have an elaborative approach to 
writing, with intuitive and scientist approaches also being common. For international students, low self-efficacy is more common as a primary approach than intuitive and scientist. The results of writing concepts, shown in Figure 2, the international and domestic students show similar trends, with Knowledge Transforming and Procrastination being the two most common processes.

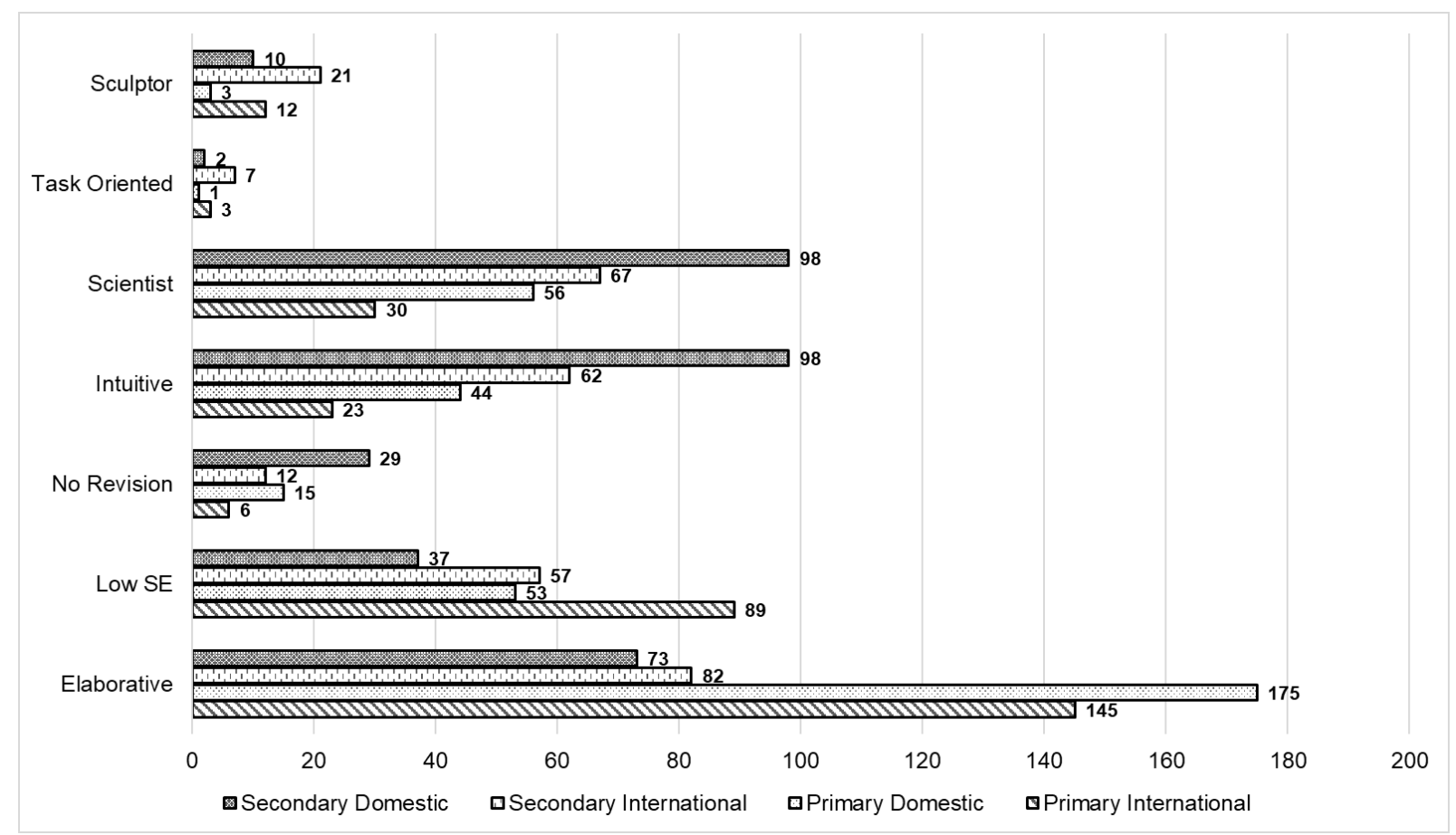

Figure 1: Primary and secondary writing processes for international and domestic engineering graduate students.

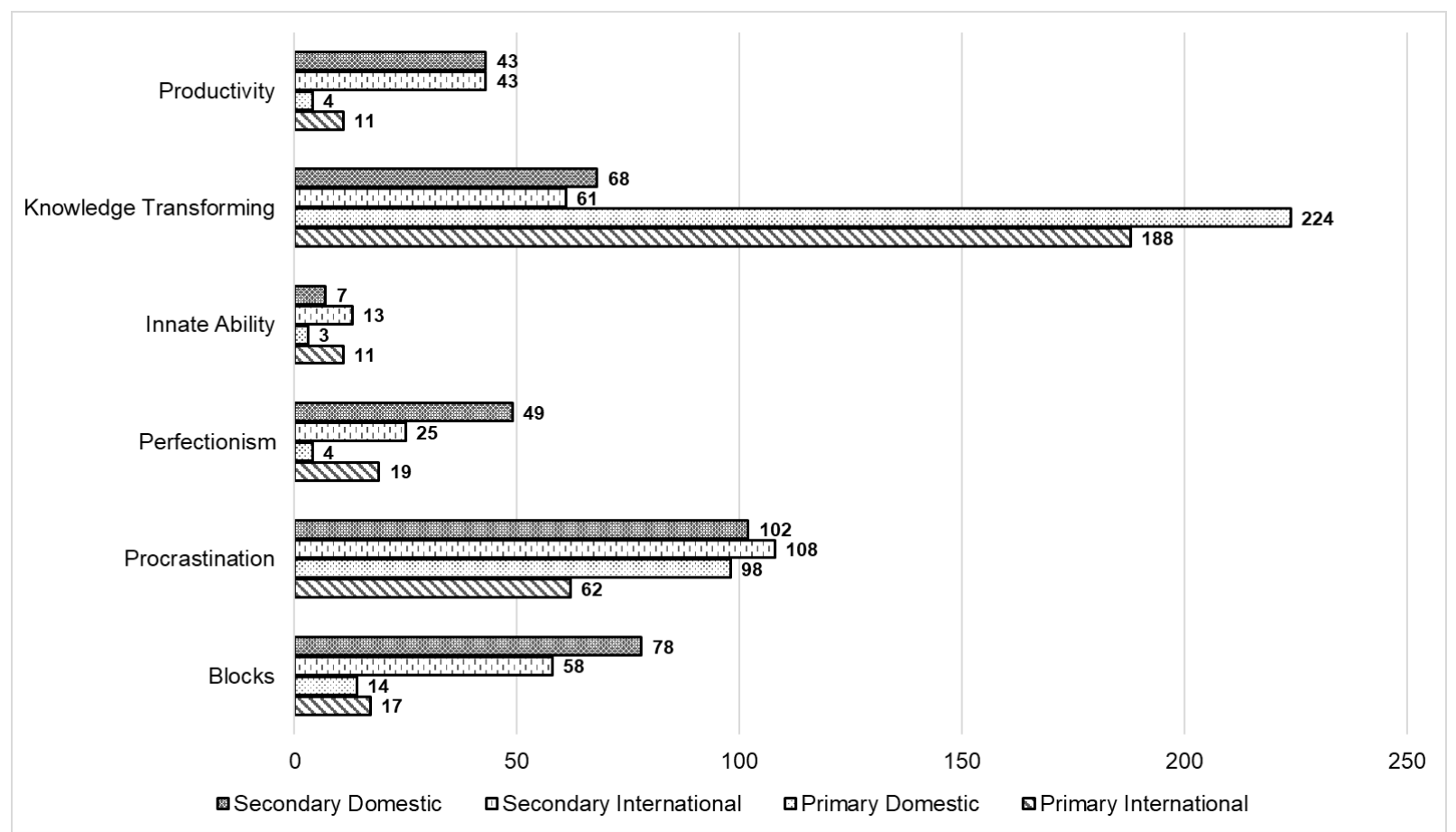

Figure 2: Primary and secondary writing concepts for international and domestic engineering graduate students. 
Table 1 shows descriptive statistics and ANOVA results comparing the domestic and international participants. The only two writing approaches that are not statistically different to some degree are Intuitive and Scientist approaches. The only two concepts that are statistically similar between the sample groups are Knowledge-Transforming and Procrastination; all others are statistically different.

\begin{tabular}{|c|c|c|c|c|c|}
\hline & & & \\
\hline & & & Mean & Std. Deviation & Significance in ANOVA \\
\hline \multirow{14}{*}{ 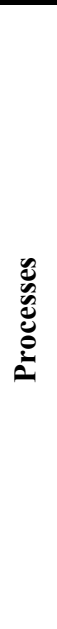 } & Elaborative & Domestic & 3.07 & 0.374 & $0.031^{*}$ \\
\hline & & International & 3.13 & 0.343 & \\
\hline & Low Self- & Domestic & 2.69 & 0.386 & $0.000 * *$ \\
\hline & efficacy & International & 2.93 & 0.353 & \\
\hline & No Revision & Domestic & 2.31 & 0.423 & $0.000 * *$ \\
\hline & & International & 2.42 & 0.371 & \\
\hline & Intuitive & Domestic & 2.88 & 0.341 & 0.491 \\
\hline & & International & 2.90 & 0.356 & \\
\hline & Scientist & Domestic & 2.89 & 0.291 & 0.682 \\
\hline & & International & 2.90 & 0.307 & \\
\hline & Task Oriented & Domestic & 2.29 & 0.251 & $0.000 * *$ \\
\hline & & International & 2.44 & 0.340 & \\
\hline & Sculptor & Domestic & 2.44 & 0.404 & $0.000 * *$ \\
\hline & & International & 2.68 & 0.373 & \\
\hline \multirow{12}{*}{ 巳̃ } & Blocks & Domestic & 2.89 & 0.837 & $0.022 *$ \\
\hline & & International & 3.03 & 0.725 & \\
\hline & Procrastination & Domestic & 3.32 & 0.937 & 0.705 \\
\hline & & International & 3.35 & 0.884 & \\
\hline & Perfectionism & Domestic & 2.72 & 0.772 & $0.002 *$ \\
\hline & & International & 2.90 & 0.723 & \\
\hline & Innate Ability & Domestic & 1.71 & 0.750 & $0.000 * *$ \\
\hline & & International & 2.26 & 0.946 & \\
\hline & Knowledge & Domestic & 4.01 & 0.511 & 0.556 \\
\hline & Transforming & International & 4.03 & 0.509 & \\
\hline & Productivity & Domestic & 2.29 & 0.747 & $0.000 * *$ \\
\hline & & International & 2.66 & 0.806 & \\
\hline
\end{tabular}

Table 1: Mean and standard deviation for each attitude for both domestic and international students and significance value comparing the two samples. $* f<0.05, * *_{f}<0.001$

\section{Discussion, Implications, and Conclusions}

From the results of primary and secondary writing attitudes for both domestic and international students, we see similar trends. But the ANOVA show that despite the similarities, the results from each group are statistically different for most attitudes. Low self-efficacy, no revision, taskoriented, sculptor, innate ability, and productivity attitudes all have a statistical significance less than f-statistic $<0.001$. More domestic students' survey results indicated tendencies toward No Revision processes than international students, which makes sense when considering the international students are most likely writing in a language that is not their first. On the other hand, the Low Self-Efficacy approach is more prevalent in international students over domestic students. 
This, along the statistically significant difference between the groups regarding the Innate Ability concept, highlights the struggles the international students have when writing in an academic context. The difficulty of writing technically in a foreign language may cause some students to doubt their own writing ability or believe that they can never improve.

Professors and advisors for engineering graduate students can use these results to better understand their students and how their attitudes towards writing differ. Student's background and prior experience with writing may influence how they develop disciplinary discourse, and this study shows that domestic and international engineering graduate students cannot be assumed to have the same writing background. One encouraging point to note, the belief that writing can be a way to generate new knowledge, the knowledge transforming concept, is the most common concept for both groups. The students know what writing should be, and it is up to professors and advisors to support their efforts to improve. Similarly, since international and domestic graduate students are not statistically different in their struggles with procrastination, interventions that seek to ameliorate or provide strategies to overcome procrastination might be first steps in approaching writing instruction.

International and domestic engineering graduate students show similar trends in primary and secondary attitudes towards writing, but a comparison between the groups show that most results are statistically different. Subtle differences between how the groups approach writing and what they believe about the process could influence the effectiveness of a "one-size-fits-all" approach to writing instruction. Tailoring writing instruction and support to account for each student's background with writing could help each student develop stronger attitudes towards writing, which, in turn develops stronger disciplinary discourse and acceptance within the discipline community. To meet the needs of instructors, we are concurrently developing and validating a "short form" of this survey that will be deployed online to help all engineering students determine their writing profile, such that they can, with the help of instructors, develop strategies to overcome their individual issues with writing.

\section{References}

[1] C. G. P. Berdanier, A. Tally, S. E. Branch, B. Ahn, and M. F. Cox, "A Strategic Blueprint for the Alignment of Doctoral Competencies with Disciplinary Expectations," Int. J. Eng. Educ., vol. 32, no. 4, pp. 1759-1773, 2016.

[2] J. Watson and J. Lyons, "Aligning Academic Preparation of Engineering Ph.D. Programs with the Needs of Industry,” Int. J. Eng. Educ., vol. 27, no. 6, pp. 1394-1411, 2011.

[3] C. G. P. Berdanier and E. Zerbe, "Correlations between graduate student writing concepts and processes and certainty of career trajectories," IEE FIE, San Jose, CA, 2018.

[4] A. J. Onwuegbuzie and K. M. T. Collins, "Writing Apprehension and Academic Procrastination among Graduate Students," Percept. Mot. Skills, vol. 92, pp. 560-562, 2001.

[5] A. J. Swart, K. Lombard, and H. de Jager, "Exploring the relationship between time management skills and the academic achievement of African engineering students - a case study," Eur. J. Eng. Educ., vol. 35, no. 1, pp. 79-89, 2010.

[6] B. Yalvac, H. D. Smith, J. B. Troy, and P. Hirsch, "Promoting Advanced Writing Skills in an 
Upper-Level Engineering Class," J. Eng. Educ., vol. 96, no. 2, pp. 117-128, 2007.

[7] G. Boyd and M. Hassett, "Developing critical writing skills in engineering and technology students," J. Eng. Educ., no. October, 2000.

[8] C. Plumb and C. Scott, "Outcomes Assessment of Engineering Writing at the University of Washington.," J. Eng. Educ., vol. 91, no. 3, pp. 333-338, 2002.

[9] M. R. Kuhn and K. Vaught-Alexander, "Context for writing in engineering curriculum," J. Prof. Issues Eng. Educ. Pract., vol. 120, no. 4, pp. 392-400, 1994.

[10] P. Zemliansky and L. Berry, "A Writing-Across-the-Curriculum Faculty Development Program: An Experience Report," IEEE Trans. Prof. Commun., 2017.

[11] K. Walker, "Integrating Writing Instruction into Engineering Courses: A Writing Center Model," J. Eng. Educ., vol. 89, no. 3, pp. 369-375, 2000.

[12] C. Hixson, W. Lee, D. Hunter, M. Paretti, H. Matusovich, and R. McCord, "Understanding the structural and attitudinal elements that sustain a graduate student writing group in an engineering department," WLN A J. Writ. Cent. Scholarsh., vol. 40, no. 5-6, pp. 18-25, 2016.

[13] G. M. Fillenwarth, M. McCall, and C. Berdanier, "Quantification of Engineering Disciplinary Discourse in Résumés: A Novel Genre Analysis with Teaching Implications," IEEE Trans. Prof. Commun., vol. 61, no. 1, pp. 48-64, 2018.

[14] S. Conrad, "A Comparison of Practitioner and Student Writing in Civil Engineering," J. Eng. Educ., vol. 106, no. 2, pp. 191-217, 2017.

[15] L. Anthony, "Writing research article introductions in software engineering: How accurate is a standard model?," IEEE Trans. Prof. Commun., vol. 42, no. 1, pp. 38-46, 1999.

[16] K. Walker, "Using genre theory to teach students engineering lab report writing," IEEE Trans. Prof. Commun., vol. 42, no. 1, pp. 12-19, 1999.

[17] B. Kanoksilapatham, "Rhetorical structure of biochemistry research articles," English Specif. Purp., vol. 24, pp. 269-292, 2005.

[18] M. Rose and K. A. McClafferty, "A Call for the Teaching of Writing in Graduate Education," Educ. Res., vol. 30, no. 2, pp. 27-33, 2001.

[19] J. A. Leydens and B. M. Olds, "Publishing in scientific and engineering contexts: A course for graduate students," IEEE Trans. Prof. Commun., vol. 50, no. 1, pp. 45-56, 2007.

[20] G. Braine, "Academic literacy and the nonnative speaker graduate student," J. English Acad. Purp., vol. 1, pp. 59-68, 2002.

[21] D. Belcher, "The Apprenticeship Approach to Advanced Academic Literacy: Graduate Students and Their Mentors," English Specif. Purp., vol. 13, no. 1, pp. 23-34, 1994.

[22] Y.-S. Cheng, "A measure of second language writing anxiety: Scale development and preliminary validation," J. Second Lang. Writ., vol. 13, pp. 313-335, 2004.

[23] K. Lonka, A. Chow, J. Keskinen, K. Hakkarainen, N. Sandstrom, and K. Pyhalto, "How to Measure PhD. Students' Conceptions of Academic Writing--and are the Related to Well-being?,' J. Writ. Res., vol. 5, no. 3, pp. 245-269, 2014.

[24] M. R. Lea and B. V Street, "The 'Academic Literacies' Model: Theory and Applications," Theory Pract., vol. 45, no. 4, pp. 368-377, 2018.

[25] A. Riazi, "Acquiring Disciplinary Literacy: A Social-Cognitive Analysis of Text Production and Learning among Iranian Graduate Students of Education," J. Second Lang. Writ., vol. 6, no. 2, pp. 105-137, 1997.

[26] E. Lavelle and K. Bushrow, "Writing Approaches of Graduate Students," Educ. Psychol., vol. 27, no. 6, pp. 807-822, 2007. 